\title{
Factors regulating postlarval settlement and juvenile microhabitat use by spiny lobsters Panulirus argus
}

\author{
William F. Herrnkind \& Mark J. Butler IV \\ Department of Biological Science, Florida State University, Tallahassee, Florida 32306, USA
}

\begin{abstract}
Clumps of highly-branched red algae Laurencia spp. serve as important settling habitat for postlarval spiny lobsters Panulirus argus and as residence for early benthic-stage juveniles. Given choice between the 2 most abundant macrophytes in Florida Bay, Laurencia spp. and the seagrass Thalassia testudinum, postlarval and juvenile lobsters chose Laurencia spp. Postlarvae apparently use intricate algal architecture as a cue for settlement, whereas juveniles use both architecture and food abundance in selecting habitat. In tethering experiments, predation on juvenile lobsters was very high on open sand, much reduced in algal clumps and seagrass, and lowest in dense algal meadows. Predation rates were similar day and night both on open sand and in vegetation. Most lobsters vacated algal clumps located within continuous algal meadows overnight, at a rate significantly higher than that from isolated algal clumps. We suggest that algal clump distribution, postlarval settling behavior, and juvenile interpatch movement and mortality contribute to the highly dispersed distribution and locally sparse abundances of early benthic juveniles.
\end{abstract}

\section{INTRODUCTION}

The spiny lobster Panulirus argus occurs throughout the subtropical western Atlantic, where it occupies shallow seagrass meadows, coral reefs, and hard substrates in water depths generally less than $100 \mathrm{~m}$ (Kanciruk 1980). Despite widespread research on adult lobsters (Kanciruk et al. 1982), the natural history of the postlarval (settling) and early benthic stages remains obscure (Witham et al. 1968, Little 1977, Little \& Milano 1980, Calinski \& Lyons 1983). Until recently, inability to locate substantial numbers of cryptic, early benthic lobsters in the field has precluded defining the settlement microhabitat and thwarted intensive ecological research.

The last planktonic larval stage (phyllosoma) of Panulirus argus metamorphoses offshore into the puerulus, or postlarva, a transparent, fast-swimming, non-feeding stage that migrates inshore where it settles to the benthos (Lewis et al. 1952, Gordon 1953, Felder et al. 1985). There, the puerulus takes on a disruptive color pattern (i.e. brown and white banding of the appendages and striping on the body) and within days metamorphoses into the first benthic instar 6 to $7 \mathrm{~mm}$ in carapace length $(\mathrm{CL}$; measured from the

(C) Inter-Research/Printed in F. R. Germany anterior margin of the carapace between the rostral horns to the posterior dorsal margin of the cephalothorax). Lobsters less than $15 \mathrm{~mm} \mathrm{CL}$ commonly reside in or under large clumps of intricately branched red algae, Laurencia spp. (both L. poitei and L. obtusa; Marx \& Herrnkind 1985a), and are among the most common benthic macrophytes of the region. Juvenile lobsters are distributed sparsely (ca $1 / 36 \mathrm{~m}^{2}$ ) in this habitat, and individuals are usually solitary (Marx \& Herrnkind 1985b). Juveniles feed on algalassociated epifauna (e.g. gastropod and bivalve molluscs, amphipod, ostracod, and isopod crustaceans, and echinoderms; Marx \& Herrnkind 1985a) and seldom forage on open substrate, even at night. Lobsters begin to move out of algal clumps and into other subtidal refuges (e.g. sponges, solution holes, undercut seagrass banks, etc.) when they reach 15 to $20 \mathrm{~mm} \mathrm{CL}$ (Andree 1981, Marx \& Herrnkind 1985a). These observations provide the basis for our experimental analysis of factors influencing postlarval spiny lobster microhabitat selection, and juvenile lobster habitat selection, local dispersal and susceptibility to predation.

We examined several physical and biotic factors likely to affect selection of settlement microhabitat by pueruli and choice of refuge by juveniles. We also 
investigated whether residency within Laurencia spp. or the seagrass Thalassia testudinum affords refuge from predators and how refuge size and spatial distribution influences residency and dispersal. Special attention was given to the comparison between Laurencia spp. and $T$. testudinum because these represent the 2 most abundant macrophytic habitats in Florida Bay, and both have been implicated as primary habitat for juvenile Panulirus argus (Eldred et al. 1972, Davis \& Dodrill 1980, Marx \& Herrnkind 1985a, b).

\section{METHODS AND MATERIALS}

All lobsters used in habitat selection experiments were collected as transparent pueruli from plankton in Tom's Harbor Channel (between Duck and Grassy Keys, Florida, USA) using a $1 \mathrm{~m}$ diameter plankton net (2.5 $\mathrm{m}$ long; $500 \mu \mathrm{m}$ mesh). Pueruli were used immediately in experiments or were reared to the benthic juvenile stage in the laboratory for later experimentation. We assumed that pueruli collected in this manner, as opposed to those harvested from Witham-type collectors (Witham et al. 1968, Phillips 1972), had not yet settled and were naive relative to Florida Bay settling habitats. We used both plankton-caught and collectortrapped animals in predation and residency/dispersal experiments.

Habitat selection/settling experiments. Laboratory experiments were used to document postlarval settling preferences and habitat preferences of early benthic juveniles. We first determined preferences of postlarvae and recently metamorphosed juveniles for different natural substrates, then tested whether food abundance or habitat architecture influenced habitat choice. Experiments were conducted in twenty 75.71 seawater aquaria with subgravel filters and a circulating current of approximately $3 \mathrm{~cm} \mathrm{~s}^{-1}$. Light was provided by overhead skylights and fluorescent lights; photoperiod was approximately $14 \mathrm{~L}: 10 \mathrm{D}$. We tested treatment combinations by alternating positions of the 2 test habitats at either end of each of the 20 aquaria. The two $20 \mathrm{~cm}$ diameter habitat patches were separated by $25 \mathrm{~cm}$ of open sand, and each patch was at least $5 \mathrm{~cm}$ from an aquarium wall. Thus, if a lobster demonstrated edge-seeking behavior, its habitat choice would be biased in favor of open sand. We provided an overabundance of food by adding a few $\mathrm{g}$ of Tetramin fish food to each habitat patch, except where indicated in food treatments. Juvenile lobsters readily consumed Tetramin; pueruli did not feed. Either a puerulus or juvenile was introduced to the center of an aquarium through a length of PVC pipe and allowed to settle to the substrate. The pipe then was withdrawn slowly and the lobster allowed to move about the tank. This technique prevented the lobster from tailflipping and facilitated 'active selection' of habitats. To conclude each experiment, we located the lobsters and recorded their positions.

Preliminary experiments indicated that once pueruli or juveniles chose a habitat, usually within $8 \mathrm{~h}$, they remained there for several days. Therefore, the juvenile lobster experiments began and ended at 2100 $\mathrm{h}$ to allow the nocturally active lobsters $24 \mathrm{~h}$ to move about and select a habitat. Experiments with pueruli also began and ended at $2100 \mathrm{~h}$ but were terminated only after pueruli ceased swimming. Most pueruli settled overnight, although one experiment continued for 7 d. In each experiment, we tested 20 lobsters on Day 1 and, usually, 20 more on Day 2. A lobster was used only once in choice experiments. Log-linear contingency tables tested the null hypothesis of equal selection for the 2 test habitats in each experiment.

(A) Natural substrate selection experiments. These experiments examined settling and habitat preferences of pueruli and juveniles given a choice between Laurencia spp. and Thalassia testudinum. Algae and seagrass were collected daily. Clumps of algae ca $20 \mathrm{~cm}$ in diameter were held in place in aquaria with monofilament strands anchored by lead sinkers (anchors were added to all test habitats for experimental balance). We created dense patches of seagrass by inserting $20 T$. testudinum shoots through $20 \times 20 \mathrm{~cm}$ grids of $1.3 \mathrm{~cm}$ mesh vexar screen and burying the screen and seagrass rhizomes under sand. Natural seagrass densities near Long Key, Florida (425 shoots $\mathrm{m}^{-2}$ ) were similar to test densities of 500 shoots $\mathrm{m}^{-2}$.

(B) Complex structure experiments. Given the postlarval and juvenile lobsters' penchant for Laurencia spp. (see results of natural substrate selection experiments), we investigated whether complex structure significantly influenced postlarval settling preference or juvenile lobster habitat selection. Simulated algae clumps made from intertwined strips of black vexar screen ( $4 \mathrm{~mm}$ mesh) were tested against a similar sized vexar mesh cone (open end buried in sand) that provided no refuge for lobsters. This test allowed us to discriminate between selection for dark, 3-dimensional objects per se, versus those that also provided physical refuge.

(C) Food abundance experiments. We expected that food was requisite to habitat selection by young spiny lobsters (Marx \& Herrnkind 1985b). This was tested by providing pueruli and juvenile lobsters both rinsed (low-food) and food-supplemented Laurencia spp. In one set of experiments, algal clumps were supplemented with Tetramin and, in a second set, with prey normally found in Laurencia spp. We tested pueruli only with algae supplemented with natural prey. Food-supplemented algal clumps contained 
$40 \%$ more food per clump than did rinsed clumps (0.36 vs $0.58 \mathrm{~g}$ dry wt.; means of 10 randomly sampled rinsed vs food-supplemented Laurencia clumpsi.

Predation-refuge experiments. To test the relative degree of security from predators afforded young lobsters by natural substrates, we tethered lobsters in the field in Laurencia spp., Thalassia testudinum, or open sand. Lobsters ( 7 to $11 \mathrm{~mm} \mathrm{CL}$ ) were tethered to a steel spike via a $20 \mathrm{~cm}$ length of $6 \mathrm{lb}$-test clear monofilament. Tethers were attached to lobsters by slipping a noose about the cephalothorax between Pereiopods 4 and 5 and affixing the noose to the carapace with superglue (Superglue Corp., Hollis, New York). The glue bond was so strong that empty tethers retrieved from the field often had fragments of carapace still attached to them. We held all tethered lobsters in aerated seawater at least $1 \mathrm{~h}$ prior to staking them in the field. To test durability of tether attachment and lobster reaction to tethering, we (1) placed cages (25 cm diam.; $1.3 \mathrm{~cm}$ mesh) over 35 tethered lobsters staked in the field, and (2) made underwater videotapes of 7 tethered lobsters individually staked on open sand. Only 1 of 35 lobsters escaped its tether when caged in the field for $12 \mathrm{~h}$. None of the videomonitored lobsters escaped during test periods of 8 to $36 \mathrm{~h}$.

Direct observation and videotape playback revealed that lobsters tethered in the open were mostly quiescent and only tugged against the tether line occasionally; they rarely tail-flipped. By day, lobsters in the open typically stood motionless or found some substrate discontinuity or drifting material to settle against or grasp. We swam around the test area at dusk and dawn, immediately before staking out and retrieving the tethers, to count and identify predatory fishes. Following each $24 \mathrm{~h}$ test, we moved the test site to another location at least $25 \mathrm{~m}$ away. We examined night vs day contrasts in predation on lobsters tethered in the open and in adjacent Laurencia clumps. We expected high daytime predation in the open and lower predation at night when lobsters are usually active and might be expected to evade visual predators. Another experiment compared predation rates on open sand, in isolated Laurencia clumps, and in Laurencia spp., and Thalassia testudinum meadows. Isolated Laurencia clumps were ca $20 \mathrm{~cm}$ in diameter; algal and seagrass meadows were $>500 \mathrm{~m}^{2}$ in area. This latter experiment contrasted the various vegetated habitats as refuges from predation; open sand results merely documented the activity of predators in the area. Prior studies (Heck \& Thoman 1981) showed the antipredator value of dense seagrass, so we expected little difference in short-term survival among lobsters tethered in seagrass or algae.

Residency/dispersal experiments. We conducted field experiments to determine duration of residency of juvenile lobsters in algae as a function of algal clump size and isolation (i.e. clump patchiness). We tested 3 conditions: (1) large isolated clumps (40 cm diam.); (2) small isolated clumps (20 cm diam.); (3) a large algal meadow $\left(>500 \mathrm{~m}^{2}\right.$ ). To create isolated clump conditions, we placed appropriately-sized Laurencia clumps at least $1 \mathrm{~m}$ apart on open sand. We selected clumps firmly attached to rock cobbles so they could be repositioned with minimal disturbance and without artificial anchors. Small and large isolated clump treatments simulated the most typical Laurencia habitat in the Florida Keys. Large, contiguous Laurencia meadows are less common, but may be important as localized areas for lobster recruitment. Therefore, $20 \mathrm{~cm}$ diam. clumps located within a contiguous algal bed served as the third treatment condition.

Young juvenile lobsters (mean $\mathrm{CL}=9 \mathrm{~mm}$ ) were placed in clear $10 \mathrm{ml}$ plastic vials filled with seawater to protect the lobsters from injury and to facilitate transfer to algal clumps. One lobster was introduced into each clump by a diver who teased an opening in the algal branches and inserted a vial and its lobster into the center of the clump. Lobsters remained quiescent in the vials and, once in the clumps, simply walked into the surrounding algae.

The small isolated clump treatment was conducted for 1,3 , and $10 \mathrm{~d}$, the large isolated clump treatment for 1 and $3 \mathrm{~d}$, and the contiguous bed treatment for $1 \mathrm{~d}$. The experiment was not continued to Day 10 in the large isolated clump treatment or to Day 3 and 10 in the contiguous bed treatment because residency times were brief and the number of available lobsters was limited. Twenty lobsters were used in each treatment and time interval for a total of 120 lobsters. At the end of each interval, we collected individual algal clumps in vexar mesh bags ( $4 \mathrm{~mm}$ mesh) and transported them to a nearby boat where the remaining lobsters were removed. While each clump was bagged, a diver searched the area under the clump and watched for fleeing lobsters. Only 1 of 47 lobsters retrieved was found under a clump; none were seen escaping. Most lobsters recaptured were found deep within the algae.

\section{RESULTS}

\section{Habitat selection/settling experiments}

Pueruli and juveniles strongly preferred Laurencia spp. over Thalassia testudinum (Table 1). Juveniles preferred food-supplemented algae to food-reduced algae, but pueruli did not discriminate between foodsupplemented and rinsed algae. Both pueruli and juveniles preferred dark colored architecturally com- 
Table 1. Panulirus argus. Experimental conditions and results from laboratory experiments on postlarval settling preferences and early benthic juvenile habitat selection. Values for habitat choice represent numbers of lobsters that chose each of 2 habitats provided

\begin{tabular}{|c|c|c|c|}
\hline Experimental condition & Habitat choice & $G^{d}$ & $\mathrm{p}$ \\
\hline \multicolumn{4}{|l|}{ Pueruli } \\
\hline Algae vs seagrass & $35: 6$ & 22.70 & $<0.005$ \\
\hline Artificial algae vs no structure & $23: 3$ & 11.76 & $<0.005$ \\
\hline Rinsed algae vs algae + food $^{b}$ & $10: 12$ & 0.18 & ns \\
\hline \multicolumn{4}{|l|}{ Juveniles } \\
\hline Algae vs seagrass & $31: 6$ & 18.49 & $<0.005$ \\
\hline Artificial algae vs no-refuge structure & $31: 1$ & 17.73 & $<0.005$ \\
\hline Rinsed algae vs algae + food $^{b}$ & $11: 25$ & 5.58 & $<0.025$ \\
\hline Rinsed algae vs algae + food $^{c}$ & $12: 24$ & 4.07 & $<0.05$ \\
\hline \multicolumn{4}{|c|}{$\begin{array}{l}\text { 'Two-way log-linear contingincy tables; } \mathrm{df}=1 \text {; Williams correction factor applied to G-statistic } \\
\text { b Algae supplemented with prey items naturally found in Laurencia spp. }\end{array}$} \\
\hline
\end{tabular}

plex structure to dark, simple structure. These results suggest that pueruli preferentially settle in architecturally complex habitats without regard to food abundance. Strong selection for structurally complex habitats is retained at the early benthic juvenile stage and appears to function along with a preference for food-rich environments.

We excluded the open sand habitat in aquaria from final analysis because no early benthic juvenile lobsters have been found in the field on open sand - an intuitively non-viable habitat for young lobsters given the lack of food and protection. Furthermore, fewer than $10 \%$ of all postlarval and juvenile lobsters in our experiments were found on sand, even though open sand constituted $68 \%$ of the exposed substrate in aquaria. All lobsters on open sand were found in aquarium corners or against walls, probably indicating attraction to edges rather than selection for sand.

\section{Predation experiments}

Day and night predation rates did not differ significantly in open areas or in Laurencia clumps (Fig. 1, Table 2). As expected, lobsters tethered in the open suffered significantly higher predation over $12 \mathrm{~h}$ than did those in algae. All but one of the survivors on open sand were found clinging to fragments of drifting vegetation. Small algal fragments visually disrupted the symmetry and shape of lobsters and, combined with their typical inactivity, probably camouflaged them from predators. Diver observations and underwater videotapes indicated that feeding fish often passed within $1 \mathrm{~m}$ of camouflaged, inactive lobsters without responding.

Comparisons among lobsters tethered on open sand versus those in Laurencia spp. and Thalassia testudinum or isolated Laurencia clumps confirmed a significant reduction of predation in vegetated areas (Fig. 1, Table 2). Predation rates in Laurencia spp. clumps and $T$. testudinum meadows were similar, but all other pairwise habitat comparisons were statistically significant (Table 2).

Approximately 3 times as many piscine predators were seen in the area near the vegetation comparison experiments as in the day-night test site. Likely predators at tether sites included grunts Haemulon spp., gray snappers Lutjanus griseus, toadfish Opsanus sp., mojarra Eucinostimous spp., and juvenile stone crabs Menippe mercenaria. We suspect that secretive predators such as portunid crabs and octopus also were present, and we observed transient predatory fishes such as jack Caranx spp. and bonnethead sharks

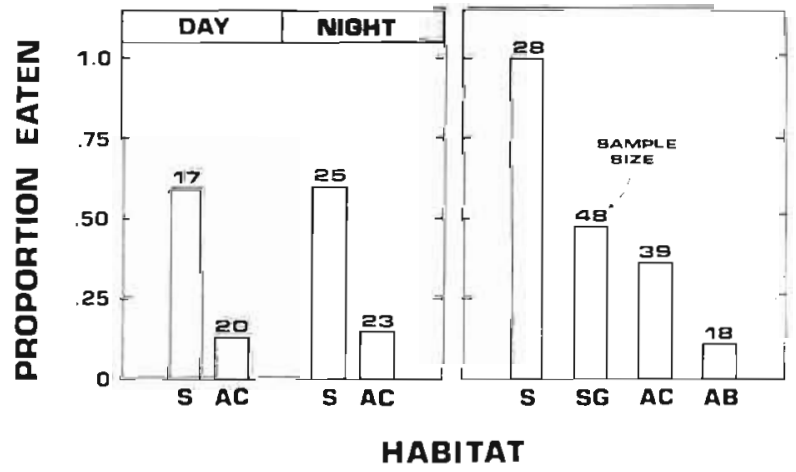

Fig. 1. Panulirus argus. Results of field tethering experiments with juveniles (7 to $11 \mathrm{~mm} C L$ ). Left: results of tethering experiments comparing predation on sand (S) and in algal clumps (AC) during day and night. Right: results of experiments comparing predation on sand and in seagrass (SG), isolated algal clumps, and in algal clumps within a large algal bed $(A B)$. Lobsters tethered for $12 \mathrm{~h}$ in both experiments 
Table 2. Panulirus argus. Results of predation-refuge experiments: Experiment 1 compared day-night predation rates in Laurencia spp. and open sand; Experiment 2 compared predation rates among 4 common habitats. A 3-factor log-linear G-test contingency table was used to analyze Experiment 1; predation (lobster present/absent), time (day/night), and habitat (algae/ sand) each have 2 levels. Two-factor log-linear G-test contingency tables were used to analyze Experiment 2 ; a $2 \times 4$ contingency table was first used to test for an overall effect, and subsequent $2 \times 2$ tables for pairwise comparisons among the 4 habitat types

\begin{tabular}{|c|c|c|c|}
\hline Test condition & df & $\mathrm{G}$ & $\mathrm{p}$ \\
\hline \multicolumn{4}{|l|}{ Experiment 1} \\
\hline Predation $\times$ time & 1 & 0.03 & ns \\
\hline Predation $\times$ habitat & 1 & 9.98 & $<0.01$ \\
\hline Time $\times$ habitat & 1 & 0.51 & ns \\
\hline Predation $\times$ time $\times$ habitat & 1 & 0.24 & ns \\
\hline \multicolumn{4}{|l|}{ Experiment 2} \\
\hline Predation $\times$ habitat & 3 & 48.81 & $<0.005$ \\
\hline Sand $\times$ seagrass & 1 & 22.06 & $<0.005$ \\
\hline Sand $\times$ algal clump & 1 & 28.38 & $<0.005$ \\
\hline Sand $\times$ algal meadow & 1 & 48.88 & $<0.005$ \\
\hline Seagrass $\times$ algal clump & 1 & 1.28 & ns \\
\hline Seagrass $x$ algal meadow & 1 & 8.58 & $<0.005$ \\
\hline Algal clump $\times$ algal meadow & 1 & 4.18 & $<0.05$ \\
\hline
\end{tabular}

Sphyrna tiburo in the area. We witnessed several successful attacks on tethered lobsters by gray snappers (estimated at $15 \mathrm{~cm}$ total length) soon after staking lobsters out in the open. Demise of the remaining lobsters tethered in open areas at the vegetation test site probably occurred well within the first $12 \mathrm{~h}$. We did not witness predation on lobsters tethered in algae or seagrass, although gray snappers and grunts spent considerable time swimming about the vegetation, apparently foraging.

\section{Residency/dispersal experiments}

Residency time of lobsters in Laurencia spp. appeared to be more a function of clump isolation than clump size (Table 3). Between 26 and $83 \%$ of the lobsters dispersed from clumps overnight; significantly more lobsters were missing from clumps within contiguous algae than from either large or small isolated clumps ( $p<0.025$; Table 3$)$. Differences between small and large isolated clumps were not statistically significant. No clump size effect was apparent after $3 \mathrm{~d}$ when 35 and $40 \%$ of the lobsters remained in small and large isolated clumps, respectively. After $10 \mathrm{~d}, 90 \%$ of the lobsters were absent from the small isolated clumps.

\section{DISCUSSION}

Juvenile spiny lobsters Panulirus argus have been reported from a variety of benthic habitats: brown and red algae (Witham at al. 1964, Marx \& Herrnkind 1985a), seagrass meadows (Eldred et al. 1972, Davis \&
Dodrill 1980), colonial bryozoans (Witham et al. 1964), sponges (Khandker 1964), and even beneath sea urchins (Davis 1971). Most collections have been of individuals $>20 \mathrm{~mm} \mathrm{CL}$, not newly settled lobsters, and many habitats from which they have been collected are ephemeral. Urchin herds, sponges, and nonvegetated fouling assemblages are probably not primary settling habitats and could not shelter the many recruits necessary to sustain adult lobster populations. The extensive seagrass meadows and algal patches present throughout the Caribbean are the most plausible sites for postlarval settlement. Seagrass meadows have been implicated as primary postlarval settling habitat for $P$. argus because trawls taken in seagrassdominated areas have produced juvenile lobsters (Eldred et al. 1972, Davis \& Dodrill 1980). Yet, most individuals captured in this manner exceed $15 \mathrm{~mm} \mathrm{CL}$, and inadvertent sampling of algae commonly interspersed with seagrass makes it difficult to ascertain the exact habitat sampled. Past SCUBA surveys have revealed a marked paucity of newly-settled juveniles amongst seagrass (Sweat 1968, Marx \& Herrnkind 1985a). Divers more reliably find postsettlement stages among Laurencia spp. in Florida Bay, albeit in locally low abundances (Marx \& Herrnkind 1985a, Herrnkind $\&$ Butler pers. obs.). Despite apparently sparse juvenile distributions even in Laurencia spp., 1 ha of patchy algal habitat could nurture an estimated 1000 lobsters $\mathrm{yr}^{-1}$ (Marx \& Herrnkind 1985a).

Laurencia spp. are probably the principal habitat of young spiny lobsters in Florida Bay. Pueruli and juveniles overwhelmingly chose Laurencia spp. over Thalassia testudinum in our laboratory selection experiments. Similar habitat specificity has been 
Table 3. Panulirus argus. Results of a field experiment testing the effects of algal clump size, isolation, and time on residency of early benthic stages. Experimental results at top of table; results of statistical analyses, log-linear G-statistic tests, at bottom. Twenty lobsters used in each treatment $x$ time experimental condition.

\begin{tabular}{|c|c|c|c|}
\hline \multirow[t]{2}{*}{ Treatment condition } & \multicolumn{3}{|c|}{ Percent absent } \\
\hline & Day 1 & Day 3 & Day 10 \\
\hline Small isolated algal clumps & $45 \%$ & $65 \%$ & $90 \%$ \\
\hline Large isolated algal clumps & $26 \%{ }^{\circ}$ & $60 \%$ & - \\
\hline Contiguous algal bed & $83 \%{ }^{b}$ & - & - \\
\hline Test condition & df & $G$ & $\mathrm{p}$ \\
\hline Day 1: Small vs large vs contiguous algal clumps & 2 & 13.40 & $<0.005$ \\
\hline \multicolumn{4}{|l|}{ Day 1: Pairwise tests of clump size } \\
\hline Large vs small clumps & 1 & 1.54 & ns \\
\hline Large vs contiguous bed & 1 & 12.98 & $<0.005$ \\
\hline Small vs contiguous bed & 1 & 6.32 & $<0.025$ \\
\hline Small clumps: Day 1 vs 3 vs 10 & 2 & 3.96 & ns \\
\hline \multicolumn{4}{|l|}{1 lobster died } \\
\hline - 2 lobsters died & & & \\
\hline
\end{tabular}

reported for $P$. interruptus, which chooses surfgrass (Phyllospadix) and red algae over other natural substrates (Parker 1972, Engle 1979), and for Homarus americanus, which prefers algal-fouled cobble over mud (Botero \& Atema 1982, Roach 1983). Habitat selection by Panulirus argus pueruli and juveniles appears to be influenced strongly by architectural complexity and, in the case of juveniles, by food abundance. Pueruli prefer complex structure regardless of food abundance, whereas juveniles choose complex, foodrich habitats. Though food abundance does not affect the settling preference of pueruli, settlement in dense vegetation indirectly may ensure ample prey following metamorphosis into juveniles.

Frequent selection of Laurencia spp. by both pueruli and juveniles raises the possibility that lobsters detect and respond to Laurencia via chemical cues; this topic warrants further research. Irrespective of chemical influences, pueruli settle in large concentrations on unfouled Witham-type collectors constructed of burlap, rope, carpeting, or air conditioning filter. Settlement on collectors of artificial materials is most consistent with the hypothesis that structural complexity is a major determinant of habitat selection. Pueruli of Panulirus interruptus also settle on Witham-type collectors, but nearly 10 times the number settle on collectors constructed of surfgrass (Serfling \& Ford 1975). Similarly, fouled Witham collectors catch more pueruli than unfouled collectors (Little \& Milano 1980). Laurencia spp. growing on suspended rope collectors deployed off the south coast of Cuba in the early 1960's also caught numerous pueruli (R. Buesa pers. comm.). It is uncertain whether young lobsters strongly select Laurencia spp., or whether this ubiquitous macrophyte simply provides the predominant source of architecturally complex habitat in Florida Bay. Although our experiments tested microhabitat selection wherein lobsters chose between 2 or more nearby habitats, we know little about the mechanics of settlement under natural conditions in which the wide-ranging pueruli may encounter a suite of habitats not necessarily in close proximity to one another.

Settlement may be further complicated by the physiological state of the puerulus. For example, it is not known whether metamorphosis to the first benthic stage is triggered by settlement, or if settlement is mediated by some physiological precursor to metamorphosis. If the timing of metamorphosis is under strict physiological control, then onset of metamorphosis may constrain the selection of appropriate settlement habitat and restrict the pueruli to whatever habitat is immediately available.

The diffuse (i.e. patchy, solitary) distribution of recently settled juveniles is potentially a product of dispersed postlarval settlement, high nomadism, and high predation - or a combination of these conditions. Available information suggests that pueruli settle in a dispersed manner due to the combined effects of regional current patterns and the patchy distribution of suitable settlement habitat. Newly settled lobsters are caught in large numbers in floating Witham collectors just offshore (Atlantic side) of the Keys (Little 1977). Large numbers of pueruli are caught in plankton nets deployed in interisland channels during night flood tides around the time of new moon (Sweat 1968), i.e. water flowing into Florida Bay. We have caught up to 150 pueruli in 60 to $90 \mathrm{~min}$ using this technique. Diving surveys of the Atlantic shallows reveal only 
limited numbers of early juveniles; either few pueruli settle here or many that settle die. These observations suggest that pueruli from offshore are shunted along the Atlantic shores and become concentrated as they funnel through narrow interisland passes. Thereafter they are scattered throughout Florida Bay by tidal and wind-driven currents. As a result, short-term local recruitment involves relatively few pueruli settling into a patchy mosaic of algal habitat.

Rapid emigration of lobsters from clumps placed within the contiguous algal bed indicates that early benthic-stage lobsters are nomadic and do not exhibit much fidelity to a 'home' clump. This interpretation is supported by videotapes of interclump movement by juvenile lobsters in aquaria. Lobsters apparently range non-directionally among algae, though open space effectively constrains interclump movement as shown by lengthier residency times in isolated clumps compared to those among contiguous algae. Marx \& Herrnkind (1985b) found that lobsters leave food-poor clumps more quickly than clumps with natural food levels. Thus, we predicted that residency time would be longer in large clumps than in small clumps, assuming large clumps contain more food. That prediction was not supported by our results. Prey counts made subsequent to the residency/dispersal experiments indicated only marginal correlation between clump size and prey number for clumps in the size range tested. Prey abundance should be manipulated in algal clumps of equal size to more adequately assess the interaction of food and residency. We did not test the influence of density on residency time because juvenile lobsters in the field are usually solitary (Marx \& Herrnkind 1985a). Several workers have reported aggressiveness between juvenile spiny lobsters (Berrill 1975, 1976, Andree 1981, Marx \& Herrnkind 1985b), but those experiments were conducted with unusually high juvenile densities (5 to 10 lobsters per algal clump or aquarium; Berrill 1975, Marx \& Herrnkind 1985b), larger size classes (Andree 1981), or size classes that probably seldom interact in nature (Berrill 1975, 1976). Dispersal rates we report could be overestimates if lobsters scored as missing from clumps did not emigrate but were eaten. Predators more likely contributed to reduced numbers over time in the isolated clumps, based on tethering results. Future field manipulations should test the effect of predation on algal residency.

Frequent movement of lobsters between algal clumps was unexpected, given the high relative risk of predation on open sand, both day and night. However, lobsters in the open appear to reduce susceptibility to predation by moving very slowly between small, temporary refuges and alternating movement with periods of quiescence. This type of behavior by small crusta- ceans is effective in reducing predation by visuallyhunting fish (Main 1985). Predation risk for lobsters in the open is, nonetheless, higher than in vegetated areas. We emphasize that predation rates we report are only relative measures recorded in representative benthic habitats and may not reflect natural predation rates. Tethering estimates are likely to be biased by the technique, which unavoidably restricts escape. Levels of predation likely vary locally and seasonally.

In the Florida Keys it is not yet possible to link puerulus settlement to subsequent populations of adult spiny lobsters (Marx in press). Knowledge of processes that direct and impinge upon recruitment and settlement of the Flonda spiny lobster is crucial to the understanding of the population dynamics of this prominent and commercially valuable species. Local patterns of postlarval recruitment, physiological plasticity in postlarval metamorphosis and settlement, and regulation of algal residency represent important topics for future research.

Acknowledgements. We thank P. Greenwood, J. Hunt, M. Keough, J. Marx, J. Schmidt, and 3 anonymous reviewers for insightful critiques of the manuscript. Field assistance was provided by D. Chittick, P. Greenwood, J. Hunt, J. Marx, R. Raney, R. Tankersley, D. Wilbur, and P. Wilbur. We thank the Sea World Center for Marine Science and Conservation, Long Key, Florida for fine logistical support. This research was supported by a Sea Grant award (R/LR-B-16) to W. F. Hermkind. Contribution No. 1035, FSU Marine Laboratory.

\section{LITERATURE CITED}

Andree, S. (1981). Locomotory activity patterns and food items of benthic postlarval spiny lobsters, Panulirus argus. $\mathrm{M}$. Sci. thesis, Florida State University, Tallahassee

Berrill, M. (1975). Gregarious behavior of juveniles of the spiny lobster, Panulirus argus (Crustacea: Decapoda). Bull. mar. Sci. 25: 515-522

Berrill, M. (1976). Aggressive behavior of post-puerulus larvae of the western rock lobster Panulirus longipes (MilneEdwards). Aust. J. mar. Freshwat. Res. 27: 83-88

Botero, L., Atema, J. (1982). Behavior and substrate selection during settling in the lobster Homarus americanus. J. Crust. Biol. 2: 59-69

Calinski, M. D., Lyons, W. G. (1983). Swimming behavior of the puerulus of the spiny lobster Panulirus argus (Latreille, 1804) (Crustacea: Palinuridae). J. Crust. Biol. 3: 329-335

Davis, G. E. (1971). Aggregations of spiny sea urchins, Diadema antillarium, as shelter for young spiny lobsters, Panulirus argus. Trans. Am. Fish. Soc. 100: 586-587

Davis, G. E., Dodrill, J. W. (1980). Marine parks and santuaries for spiny lobster fishery management. Proc. Gulf. Caribb. Fish. Inst. 32: 194-207

Eldred, B., Futch, C. R., Ingle, R. M. (1972). Studies of juvenile spiny lobsters, Panulirus argus, in Biscayne Bay, Florida. Fla Dept Nat. Res. Mar. Res. Lab. Spec. Rep. 35: 1-16

Engle, J. M. (1979). Ecology and growth of juvenile California spiny lobster, Panulirus interruptus (Randall). Ph.D. Dissertation, Univ. Southern California, Los Angeles 
Felder, D. L., Martin, J. W., Goy, J. W. (1985). Patterns in early postlarval development of decapods. In: Wenner, A. M. (ed.) Crustacean issuses. Vol. 2, Larval growth. A. A. Balkema Press, Rotterdam, p. 163-225

Gordon, I. (1953). On the puerulus stage of some spiny lobsters (Palinuridae). Bull. Brit. Mus. nat. Hist. (Zool.) 2: $17-42$

Heck, K. L., Thoman, T. A. (1981). Experiments on predatorprey interactions in vegetated aquatic habitats. J. exp. mar. Biol. Ecol. 53: 125-134

Kanciruk, P. (1980). Ecology of juvenile and adult Palinuridae (spiny lobsters). In: Cobb, J. S., Phillips, B. F. (ed.) The biology and management of lobsters, Vol. 2. Academic Press, New York, p. 59-92

Kanciruk, P., Herrnkind, W. F., Phillips, B. F., Arnaud, P. M. (1982). An indexed bibliography of the spiny (rock) lobsters (Decapoda: Palinuridae). CSIRO Rep. 141: 1-225

Khandker, N. A. (1964). Sponge as shelter for young spiny lobster. Trans. Am. Fish. Soc. 93: 204

Lewis, J. B., Moore, H. B., Babis, W. (1952). The postlarval stages of the spiny lobster Panulirus argus. Bull. mar. Sci. 2: $324-337$

Little, E. J. Jr. (1977). Observations on recruitment of postlarval spiny lobsters, Panulirus argus, to the south Florida coast. Fla mar. Res. Publ. 29: 1-35

Little, E. J. Jr., Milano, G. R. (1980). Techniques to monitor recruitment of postlarval spiny lobsters, Panulirus argus, to the Florida Keys. Fla mar. Res. Publ. 37: 1-16

Main, K. (1985). The influence of prey identity and size on selection of prey by two marine fishes. J. exp. mar. Biol. Ecol. 88: 145-152

Marx, J. M., Herrnkind, W. F. (1985a). Macroalgae (Rhodo- phyta: Laurencia spp.) as habitat for young juvenile spiny lobsters, Panulirus argus. Bull. mar. Sci. 36: 423-431

Marx, J., Herrnkind, W. F. (1985b). Factors regulating microhabitat use by young juvenile spiny lobsters, Panulirus argus: food and shelter. J. Crust. Biol. 5: 650-657

Marx, J. (in press). Recruitment and settlement of spiny lobster pueruli in south Florida. Can. J. Fish. Aquat. Sci.

Parker, K. P. (1972). Recruitment and behavior of puerulus larvae and juveniles of the California spiny lobster, Panulirus interruptus (Randall). M.Sci. thesis, San Diego State College, San Diego

Phillips, B. F. (1972). A semi-quantitive collector of the puerulus larvae of the western rock lobster Panulirus longipes cygnus George (Decapoda: Palinuridae). Crustaceana 22: 147-154

Roach, S. G. (1983). Survivorship, growth, and behavior of juvenile lobsters Homarus americanus Milne-Edwards in controlled environments in nature. Nova Scotia Dept. Fish. Mar. Res. Tech. Rep. Ser. 83-02: 1-60

Serfling, S. A., Ford, R. F. (1975). Ecological studies of the puerulus larval stage of the California spiny lobster, Panulirus interruptus. Fish. Bull. U. S. 73: 360-377

Sweat, D. E. (1968). Growth and tagging studies on Panulirus argus (Latreille) in the Florida Keys. Fla Bd Conserv. Mar. Res. Lab. Tech. Ser. 57: 1-30

Witham, R., Ingle, R. M., Joyce, E. A. Jr. (1968). Physiological and ecological studies of Panulirus argus from the St. Lucie estuary. Fla Bd Conserv. Mar. Res. Lab. Tech. Ser. 53: $1-31$

Witham, R., Ingle, R. M., Sims, H. W. Jr. (1964). Notes on postlarvae of Panulirus argus. Q. J. Fla Acad. Sci. 27: 289-297 